\title{
Study on Mechanical Properties and Fire Resistance of Epoxy Nanocomposite Reinforced with Environmentally Friendly Additive: Nanoclay I.30E
}

\author{
Tuan Anh Nguyen (D, Thi Mai Huong Pham, Thi Huong Dang, Thi Hanh Do, \\ and Quang Tung Nguyen \\ Faculty of Chemical Technology, Hanoi University of Industry (HaUI), No. 298 Cau Dien, North District Tu Liem, \\ Hanoi, Vietnam \\ Correspondence should be addressed to Tuan Anh Nguyen; anhnt@haui.edu.vn
}

Received 23 January 2020; Revised 2 March 2020; Accepted 17 April 2020; Published 30 April 2020

Academic Editor: Shafaqat Ali

Copyright (C) 2020 Tuan Anh Nguyen et al. This is an open access article distributed under the Creative Commons Attribution License, which permits unrestricted use, distribution, and reproduction in any medium, provided the original work is properly cited.

\begin{abstract}
The main purpose of this study is to complete the research process of dispersing nanoclay I.30E (montmorillonite) into epoxy Epikote 240 by mechanical method combined with energy-saving ultrasonic method. We investigate appropriate dispersion conditions such as stirring speed, mechanical stirring temperature, ultrasonic stirring time, and ultrasonic stirring capacity, which affect the mechanical properties and fire resistance of nanocomposite materials. The nanoclay contents studied were 1,2,3, and 4\% by weight, and the methods used in this study are FE-SEM; XRD; and flame-retardant evaluation methods: LOI, UL 94HB. The mechanical properties were studied: tensile strength, flexural strength, compression strength, and impact resistance Izod. The dispersion method was recommended to stir mechanically at a speed of $3000 \mathrm{rpm}$ at $80^{\circ} \mathrm{C} \mathrm{for} 8$ hours and then conduct ultrasonic vibrations for 6 hours at $65^{\circ} \mathrm{C}$. The results showed that epoxy Epikote 240/nanoclay I.30E nanocomposite material had mechanical properties and improved fire retardancy with a small amount of nanoclay I.30E added ( $2 \%$ by weight): tensile strength of $63.5 \mathrm{MPa}$ (increased by $13.59 \%$ ), flexural strength of $116.80 \mathrm{MPa}$ (increased by $34.63 \%$ ), compressive strength of $179.67 \mathrm{MPa}$ (increased by $15.11 \%$ ), impact resistance Izod of $12.81 \mathrm{KJ} / \mathrm{m}^{2}$ (increased by $80.16 \%$ ), oxygen limit of $23.7 \%$, and combustion rate of $24.5 \mathrm{~mm} /$ $\mathrm{min}$; according to UL $94 \mathrm{HB}$, the combustion rate reached $22.59 \mathrm{~mm} / \mathrm{min}$.
\end{abstract}

\section{Introduction}

Polymers-nanoclay nanocomposites, discovered by Toyota research group were found to be promising owing to their improved mechanical properties [1]. Combining polymer materials with nanoclay at different contents enhanced their mechanical properties and fire resistance [2]. Nanoclay (montmorillonite, MMT) was dispersed with contents $(0,2$, $4,6,10$, and 15\%) by Lam et al. This result showed that the hardness improvement was the best for nanoclay content of $4 \%$. If the amount of nanoclay is increased, the hardness will be much reduced. Most studies have shown that adding a small amount of nanoclay can improve the mechanical properties; however, there is also a limit of enhancing properties to optimal level [3]. Ferreira et al. [4] studied the dispersion of nanoclay with structure into epoxy at ratios of $1 \%$ and $3 \%$. The results showed that the sample with $1 \%$ nanoclay content had about $6 \%$ higher tensile strength than the sample with $3 \%$ nanoclay content. Nanoclay dispersion was evaluated by X-ray diffraction method and SEM images. Tomić et al. studied the mechanical properties of epoxy nanoclay/nanocomposite materials [5]. Epoxy/nanoclays manufactured with the contents of $1,3,5,8$, and $10 \%$ nanoclay by weight were denoted as NC1, NC3, NC5, NC8, and NC10, respectively. The sample containing $10 \%$ nanoclay was fabricated by mechanical stirring method at a speed of $1000 \mathrm{rpm}$ for 1 hour at room temperature and 1.5 hours at $60^{\circ} \mathrm{C}$, followed by ultrasound stirring at $25^{\circ} \mathrm{C}$ for 10 
minutes. Azeez et al. [6] studied the properties of MMT/ epoxy nanocomposites. MMT/epoxy nanocomposite is known for its high thermal stability and flame-retardant properties. The improved thermal stability is due to the effects of the nanoclay layer. The slowing of evaporation of volatile products in nanocomposite is due to the blocking of silicate layers in the polymer substrate. Improving the thermal stability of nanoclay nanocomposites/polymers has been reported with various organic nanoclay types (organoclays) and polymer substrates. Zainuddin et al. [7] reported that the temperature causing deformation and thermal decomposition increased from $124^{\circ} \mathrm{C}$ and $348^{\circ} \mathrm{C}$ to $133^{\circ} \mathrm{C}$ and $373^{\circ} \mathrm{C}$, respectively, for nanoclay/epoxy nanocomposite with $5 \%$ nanoclay by weight when compared with original epoxy resin background. In this study, we dispersed nanoclay I30E into Epikote 240 epoxy resin in different dispersion modes, thereby giving the most suitable method of fabrication. Nanoparticles-reinforced polymer composites have been widely investigated, indicating significant improvements in mechanical, thermal, and physical properties. The effect achieved by using nanoclay has been observed, even for low nanoclay content, for example, $1 \%$ to $3 \%$ wt. Montmorillonite clay (MMT) is the most widely used material for preparation of nanopolymer materials due to its high frame rate and economic advantages [8].

In recent years, the preparation of modified two-dimensional nanomaterials as flame retardants has gained widespread attention in this area. Because of their unique layering structure, bidirectional nanomaterials can generally improve the mechanical properties of polymers through uniform dispersion, and they can create effective physical barriers in the matrix to improve the thermal stability of polymers [9]. In a number of new studies using nanoclay in materials manufacturing, future application orientations are likely to include health (biomedical applications), safety (food packaging), environment (biodegradable material), and environmentally friendly fire resistance $[10,11]$.

In this study, we have dispersed nanoclay I30E into Epikote 240 epoxy resin in different dispersion modes, thereby giving the most suitable manufacturing method, based on the evaluation of mechanical properties, fire retardation, structural morphology, and X-ray diffraction.

\section{Materials and Methods}

2.1. Materials. The epoxy Epikote 240 was provided by Shell Chemicals (USA). EP240 has low viscosity; based on a blend of bisphenol A resin and bisphenol B resin, with epoxy group of $24.6 \%$, molecular weight $(\mathrm{Mw})$ of $5100-5400 \mathrm{mmol} / \mathrm{kg}$, and density of $1.12 \mathrm{~g} / \mathrm{ml}$, viscosity at $25^{\circ} \mathrm{C}$ is $0.7-1.1 \mathrm{~Pa} \cdot \mathrm{s}$. Diethylenetriamine (DETA) received from Dow Chemical (USA) has a density of $0.95 \mathrm{~g} / \mathrm{ml}$, boiling point of $207^{\circ} \mathrm{C}$, and $\mathrm{Mw}$ of $103 \mathrm{mmol} / \mathrm{kg}$ and was used directly without any further purification. Nanoclay I.30E (Nanocor, USA) is a surface-changing montmorillonite (MMT) mineral that will disperse into nanoparticles in epoxy resin systems. Dispersion creates a mixture close to the molecule often called nanocomposite. This new composite model shows enhanced strength, heat, and barrier properties. I.30E is provided in the form of white powder dispersed into thin particles that are almost transparent in the plastic matrix.

\subsection{Methods}

2.2.1. Sample Preparation and Characterization. Nanoclay I.30E was dried for 1 hour at $80^{\circ} \mathrm{C}$ before being mixed with epoxy Epikote 240. The nanoclay contents surveyed were $1,2,3$, and $4 \%$ by weight dispersed in epoxy Epikote 240 at $80^{\circ} \mathrm{C}$, by mechanical stirring at a speed of 3000 (rpm) for 8 hours. After that, the mixture was stirred ultrasonically for 60 minutes with $50 \%$ of the machine capacity, at room temperature. Air bubbles were then removed from the mixture by a vacuum device for 15 minutes, followed by supplementing with diethylenetriamine (DETA) curing agent and mechanical stirring at $60-80 \mathrm{rpm}$ for 10 minutes. Curing agent was mixed well into the mixture, and the mixture was poured into stainless steel mold; after 24 hours, it was heated for $3 \mathrm{~h}$ at $80^{\circ} \mathrm{C}\left( \pm 2^{\circ} \mathrm{C}\right)$. After 7 days, the mechanical properties and the fire resistance of the samples were determined.

\subsubsection{Characterizations}

(i) Limiting oxygen index (LOI) according to ASTM D2863-12 and JIS K720 standard (Japan): the sample bars used for the test were $150 \times 6.5 \times 3 \mathrm{~mm}^{3}$.

(ii) The horizontal burning tests (UL-94HB): standard bar specimens were $125 \pm 5 \mathrm{~mm}$ long and $13.0 \pm 0.5 \mathrm{~mm}$ wide and were provided in the minimum thickness, $3.0(-0.0+0.2) \mathrm{mm}$ thick (ASTM D635-12).

(iii) Combustion resistance: the apparatus is specifically designed for combustion and incandescence resistance of thermoplastics, thermosetting, rigidity, and laminates. It was designed and built to meet the following standards: ASTM D 757; specimen's dimensions $3.17 \times 12.7 \times 121 \mathrm{~mm}^{3}$; maximum temperature $950^{\circ} \mathrm{C}$.

(iv) The combustion rate was measured by COMBUSTION RESISTANCE COD 6145000 according to ASTM D757-77 standard. Specimen's dimensions were $3.17 \times 12.7 \times 121 \mathrm{~mm}^{3}$.

(v) Flexural strength was determined according to ISO 178-1993 standard in Instron (USA) equipment with crosshead speed of $2 \mathrm{~mm} / \mathrm{min}$, temperature of $25^{\circ} \mathrm{C}$, and humidity of $75 \%$. Specimen size for ISO is $100 \times 15 \times 4 \mathrm{~mm}^{3}$.

(vi) Compressive properties were determined by using three-point bending test specimens with dimensions of $15 \times 10 \times 10 \mathrm{~mm}^{3}$ according to ISO 178 1993.

(vii) Izod impact strength was determined according to ASTM D265 standard in Tinius Olsen (USA). Specimen size: the standard specimen for ASTM is 
$64 \times 12.7 \times 3.2 \mathrm{~mm}^{3} \quad\left(2 \frac{1}{2} \times 1 / 2 \times 1 / 8\right.$ inch $)$ Izod sample geometry: $2 \mathrm{~mm}$.

(viii) Tensile properties were determined by using threepoint bending test specimens according to ISO 178. Specimen size for ISO is $10 \times 4 \times 80 \mathrm{~mm}^{3}$.

(ix) The morphology of the samples was carried out by scanning electron microscope (SEM, Evacseq error codes, S-4800, Japan). Structural characterizations were studied by X-ray diffraction (XRD, D8-Advance, Bruker, Germany).

(x) TEM was taken with a voltage of $80 \mathrm{kV}$; can be taken at a magnification of 100.000, 150.000, and 200.000 times; and was performed in the Department of Superstructure Analysis, Department of Virus, Central Institute of Hygiene and Epidemiology.

\section{Results and Discussion}

\subsection{The Effect of Nanoclay Content on the Mechanical and Flame-Retardant Properties of Epoxy Epikote 240/ Nanoclay I.30E Nanocomposite Materials}

3.1.1. The Survey of Structural Morphology and X-Ray Diffraction of Epoxy E 240/I.30E Nanocomposite Materials. Nanoclay I.30E (with 1, 2, 3, and 4\% mass) was dispersed into epoxy Epikote 240 by mechanical stirring method at $3000 \mathrm{rpm}$ at $80^{\circ} \mathrm{C}$ for 8 hours; afterward, the ultrasonic stirring continued for 60 minutes, with $50 \%$ capacity value, and the mixture was kept at $25-30^{\circ} \mathrm{C}$ during ultrasonic stirring. To study the dispersion ability of nanoclay in epoxy, structural morphological survey (TEM, FE-SEM) and X-ray diffraction method (Figures 1 and 2) were conducted. Sample with $2 \%$ nanoclay showed that dispersion by highspeed mechanical stirring method, combined with ultrasonic stirring for 60 minutes, made nanoclays peel and split into layers completely. Particularly for materials containing 3\% nanoclay, nanoclay layers in some areas still had small clusters alternating in epoxy resin, proving that dispersion phenomenon has not been complete (Figure 1).

Schematic X-ray diffraction diagram of epoxy Epikote $240 /$ nanoclay I.30E nanocomposite materials is shown in Figure 2. The figure shows the XRD diagram of nanoclay I.30E at $2 \theta=40$ corresponding to the basic distance $d=22.128, \AA=2.2128 \mathrm{~nm}$. This picture does not appear on the X-ray diffraction diagram of nanocomposite samples with $2 \%$ nanoclay by weight. This proved that the macromolecular circuits of epoxy were inserted into the space between the nanoclay layers, increasing the distance $d$, resulting in the structure of nanoclay being changed, specifically layer peeling.

3.1.2. Mechanical and Flame-Retardant Properties of Epoxy Epikote 240/Nanoclay I.30E Nanocomposite Materials. The effect of nanoclay content on mechanical properties of epoxy Epikote 240/nanoclay I.30E nanocomposite materials is presented in Table 1.
It was found from Table 1 that, for $2 \%$ nanoclay I.30E by weight, mechanical properties were significantly improved, with tensile strength of $63.05 \mathrm{MPa}$ (increased by $13.59 \%$ ), bending strength of $116.80 \mathrm{MPa}$ (increased by $34.63 \%$ ), compressive strength of $179.67 \mathrm{MPa}$ (increased by $15.11 \%$ ), and Izod impact resistance of $12.81 \mathrm{~kJ} / \mathrm{m}^{2}$ (increase by $80.16 \%)$.

To study the causes of increasing mechanical strength of materials, FE-SEM images (Figure 3) of broken surfaces showed different fracture surfaces for different nanoclay ratios (0-4\%). The broken surface of pure epoxy Epikote 240 is smooth and the deviation of cracks is not high.

The presence of nanoclay in epoxy Epikote 240 increased the roughness of the broken material surface, and the development path of the crack changed because of the presence of nanoclay; therefore, the propagation of cracks was more difficult to avoid a stress concentration, thus contributing to the reduction of cracks in epoxy Epikote 240.

However, when the nanoclay content was increased to 3 or $4 \%$ nanoclay I.30E, aggregate nanoclay particles appeared in some positions on the interface of nanoclay I.30E/epoxy Epikote 240 (residual nanoclay particles exist, forming separate phase breaking uniform structure); the cracks were increased, would go to those weaknesses, and were generated by convergence leading to deterioration of mechanical properties. In the nanocomposite sample with $1 \%$ nanoclay I.30E, the broken surface has hardly seen much nanoclay because a small amount of nanoclay was added.

FE-SEM images of epoxy Epikote 240/nanoclay I.30E nanocomposite materials are shown in Figure 3. The figure shows that the fractured surface FE-SEM image of pure epoxy resin is smooth, indicating that crack development is favorable when there is an external force applied. Nevertheless, by gradually adding nanoclay with different nanoclay contents, the broken surface of the material becomes coarser than that of the original epoxy Epikote 240. Thus, the cracks were faced with nanoclay layers and, as a result, the path of the crack would change direction or be interrupted; therefore, it is necessary to provide a greater energy in order to deform the material, leading to an increase in the mechanical strength of the nanocomposite material.

With $2 \%$ of nanoclay I.30E content, many cracks can be seen clearly and cracks tend to be bent. However, if the nanoclay content exceeds the threshold (3 and $4 \%$ by weight), it will lead to a decrease in the compatibility with epoxy Epikote 240 and the accumulation of nanoclay particles (Figure 3); the amount of residual nanoclay created holes inside the material, which reduced the mechanical strength compared with samples with $2 \%$ nanoclay I.30E by weight. Hence, by just using $2 \%$ nanoclay I.30E, compared with epoxy Epikote 240 in nanocomposite materials, nanostructured materials separated and interlaced, and mechanical properties were obtained at a high level with significantly improved mechanical strength compared with epoxy Epikote 240 polymer materials.

The effect of nanoclay content on the flame-retardant properties of epoxy Epikote 240/nanoclay I.30E nanocomposite materials is presented in Table 2. 


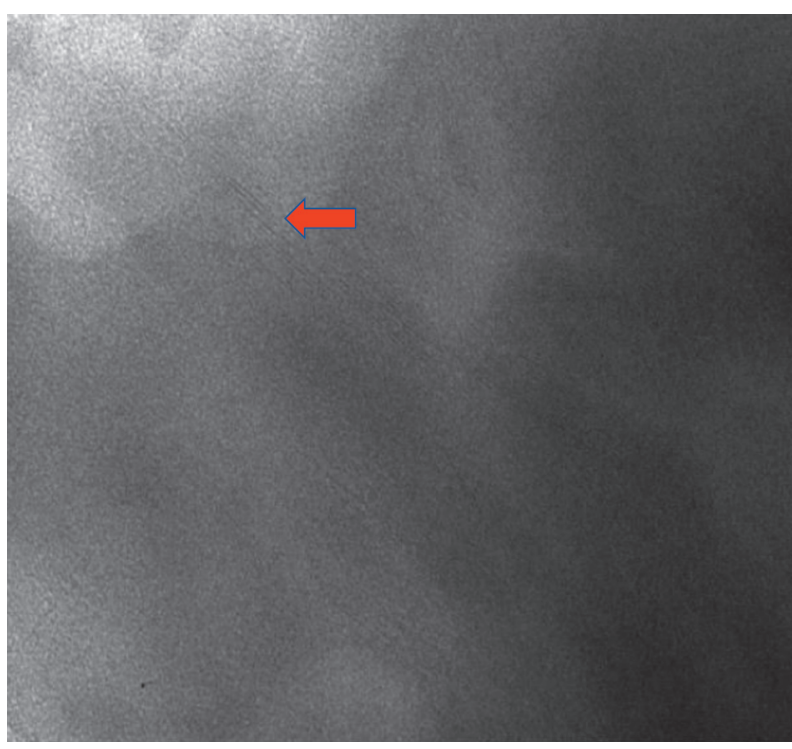

Nano clay 2YI30E - 005

Print Mag: $208000 \times$ @ $51 \mathrm{~mm}$

(a)

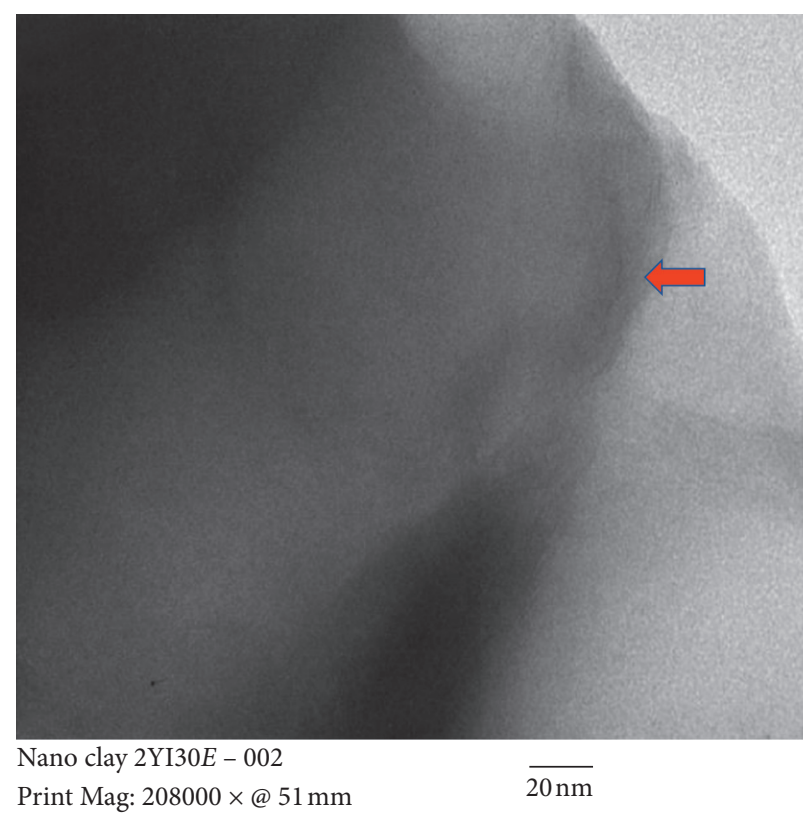

(b)

FIGURE 1: TEM image of epoxy Epikote 240/nanoclay I.30E nanocomposite material: (a) 2\% wt nanoclay I.30E, (b) $3 \%$ wt nanoclay I.30E.

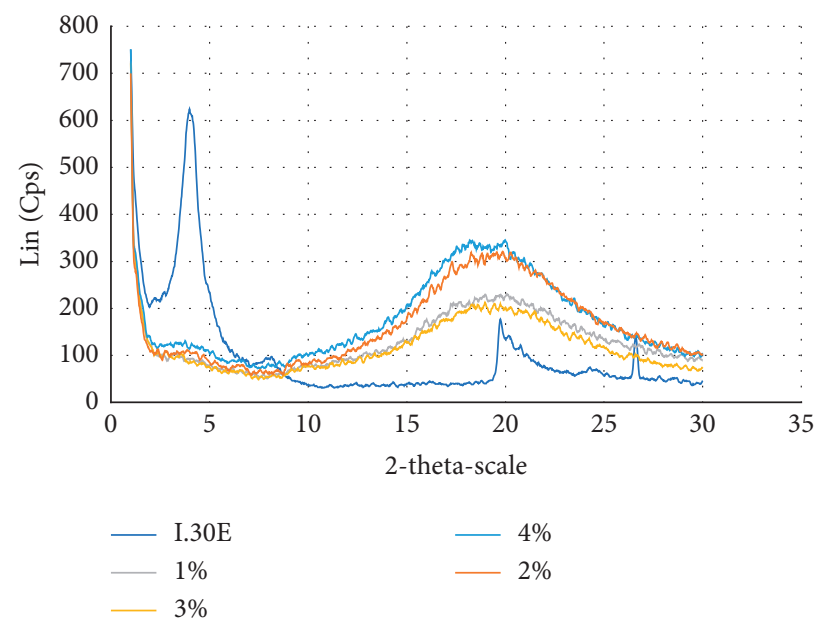

FIGURE 2: XRD diagram of pure nanoclay and epoxy Epikote 240/nanoclay I.30E nanocomposite materials.

TABLE 1: Mechanical strength of epoxy Epikote 240/nanoclay I.30E nanocomposite material with different nanoclay I.30E contents.

Sample code wt\% nanoclay I.30E Tensile strength (MPa) Flexural strength (MPa) Compressive strength (MPa) Impact strength

\begin{tabular}{llcccc} 
& & & & $\left(\mathrm{kJ} / \mathrm{m}^{2}\right)$ \\
Neat epoxy & 0 & 55.90 & 86.75 & 156.08 & 7.11 \\
NC $1^{*}$ & 1 & 58.28 & 87.30 & 152.30 & $\mathbf{1 0}$ \\
NC 2 & $\mathbf{2}$ & $\mathbf{6 3 . 5 0}$ & $\mathbf{1 1 6 . 8 0}$ & $\mathbf{1 7 9 . 6 7}$ & 12.81 \\
NC 3 & 3 & 59.60 & 97.00 & 157.32 & 11.27 \\
NC 4 & 4 & 58.91 & 79.90 & 170.43 & 10.41 \\
\hline
\end{tabular}

*NC 1: epoxy Epikote 240/nanoclay I.30E nanocomposite material with nanoclay I.30E of $1 \mathrm{wt} \%$.

Table 2 shows that epoxy Epikote 240/nanoclay I.30E nanocomposite with $2 \%$ nanoclay I.30E achieved the best fire resistance. The result of the process of nanoclay dispersion in epoxy Epikote 2400 clearly affected the improvement of fire resistance for nanocomposite materials. 


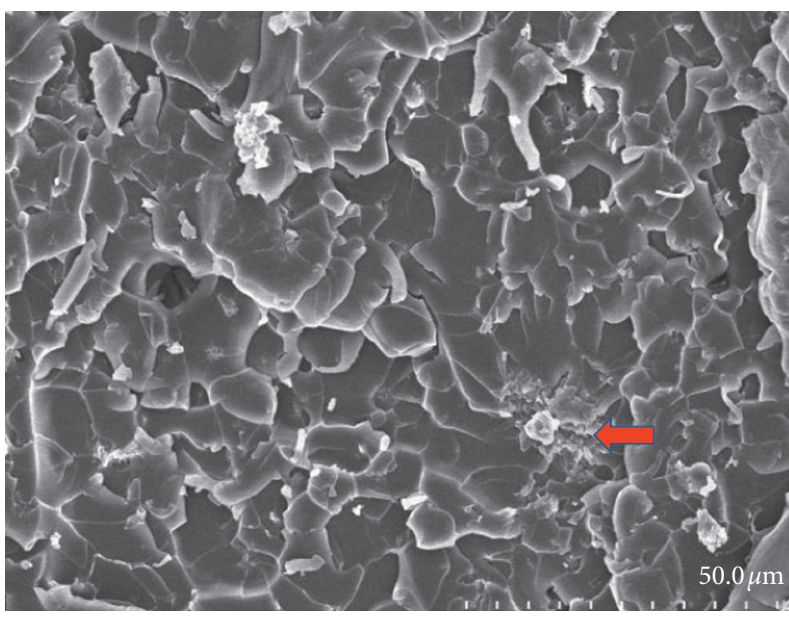

(a)

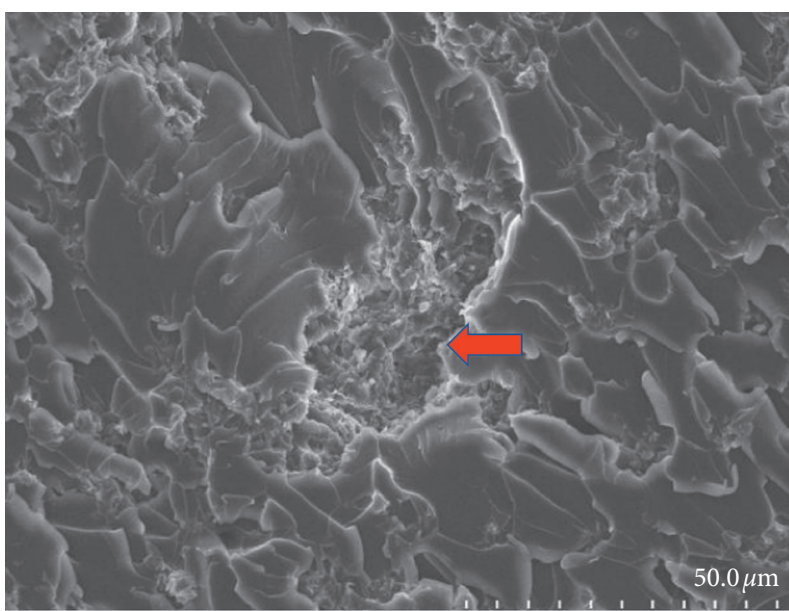

(c)

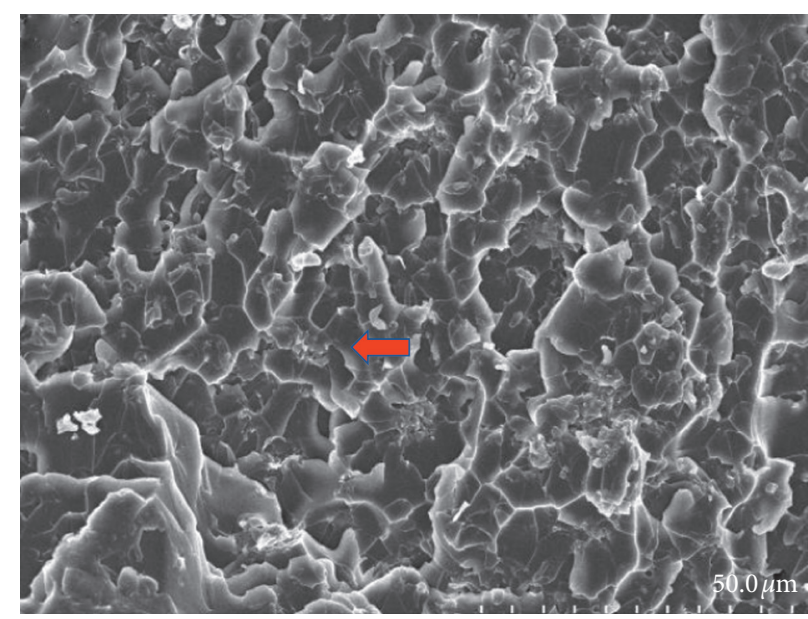

(b)

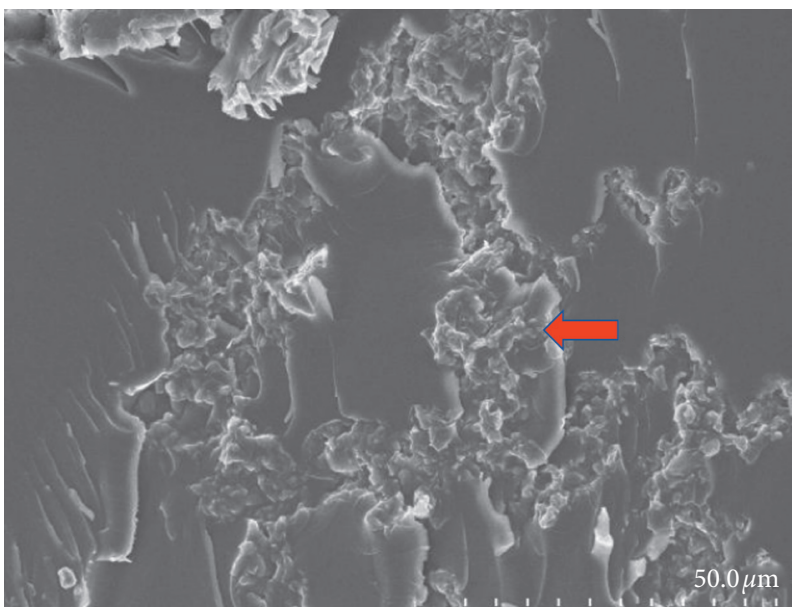

(d)

FiguRE 3: FE-SEM image of epoxy Epikote 240/nanoclay I.30E nanocomposite materials: (a) $1 \%$ wt nanoclay, (b) $2 \%$ wt nanoclay, (c) $3 \%$ wt nanoclay, and (d) $4 \%$ wt nanoclay.

TABLE 2: Results for flammability tests (reaction to small flame) oxygen index (OI) and UL 94 for nanocomposites.

\begin{tabular}{|c|c|c|c|c|}
\hline Epoxy Epikote 240/nanoclay I.30E nanocomposites & $\mathrm{wt} \%$ nanoclay I.30E & LOI $\left(\operatorname{vol} \% \mathrm{O}_{2} \pm 2 \sigma\right)$ & $\begin{array}{l}\text { Combustion } \\
\text { rate }(\mathrm{mm} / \mathrm{min})\end{array}$ & $\begin{array}{l}\text { UL94 HB } \\
(\mathrm{mm} / \mathrm{min})\end{array}$ \\
\hline Neat epoxy & 0 & 20.6 & 28.41 & - \\
\hline NC 1 & 1 & 21.4 & 27.80 & 26.07 \\
\hline NC 2 & 2 & 23.7 & 24.50 & 22.59 \\
\hline NC 3 & 3 & 22.8 & 25.76 & 23.45 \\
\hline NC 4 & 4 & 21.9 & 25.05 & 24.55 \\
\hline
\end{tabular}

A protective layer like a fence is created by nanoclay particles that are inherently heat-resistant and heat-retaining, which slowed the diffusion of oxygen, prevented volatile substances from burning from the inside of material, and limited the heat transfer process to the material, thus making the time of the combustion decrease. Thus, $2 \%$ of nanoclay I.30E weight is the most suitable content for the epoxy Epikote 240 nanocomposite material to ensure mechanical strength and fire retardancy. The results of mechanical strength and fire retardation indicated that the dispersion of nanoclay into epoxy Epikote 240 has an effect on mechanical strength and fire resistance.
3.2. The Effect of Temperature during Mechanical Stirring on Mechanical and Flame-Retardant Properties of Epoxy Epikote 240/Nanoclay I.30E Nanocomposite Materials

3.2.1. The Survey of Structural Morphology of Epoxy Epikote 240/Nanoclay I.30E Nanocomposite Materials. Temperature is one of the factors that make it easier to disperse nanoclay I.30E in epoxy Epikote 240. Therefore, examining the effect of temperature on the dispersion level of nanoclay I.30E is necessary. We carried out mechanical stirring at a speed of $3000 \mathrm{rpm}$ for 8 hours; surveying at different mechanical stirring temperature conditions of 
$50^{\circ} \mathrm{C}, 60^{\circ} \mathrm{C}, 70^{\circ} \mathrm{C}$, and $80^{\circ} \mathrm{C}$; and then ultrasonic stirring for 60 minutes, maintaining $50 \%$ capacity at $25-30^{\circ} \mathrm{C}$. The dispersion of nanoclay I.30E in epoxy Epikote 240 was tested by FE-SEM method of fractured surface. The morphology of the fractured surface of nanocomposite is presented in Figure 4. The figure shows that, for the mechanically stirred sample at $80^{\circ} \mathrm{C}$, the broken surface of the material becomes rough and has the interlaced overlapping cracks because of the presence of nanoclay I.30E in epoxy Epikote 240 background. Hence, while the temperature of the mechanical stirring process increases, the number of cracks increases, having a denser density, and as a result, at $80^{\circ} \mathrm{C}$, the cracks are the most. In Figure 4 , at $80^{\circ} \mathrm{C}$, the rough surface and the number of cracks are the highest, and the nanoclays are uniformly dispersed in epoxy Epikote 240 substrate without accumulation as the remaining samples (some nanoclay parts remain microsized in epoxy Epikote 240).

\subsubsection{The Effect of Temperature during Mechanical Stirring} on Mechanical and Flame-Retardant Properties of Epoxy Epikote 240/Nanoclay I.30E Nanocomposite Materials. The temperature of mechanical stirring is one of the important parameters for nanoclay I.30E dispersion.

The effect of temperature during mechanical stirring on mechanical properties of epoxy Epikote 240/nanoclay I.30E nanocomposite materials is presented in Table 3.

The result in Table 3 shows that, when the temperature increases, the mechanical strength increases; at $80^{\circ} \mathrm{C}$, high results are obtained: tensile strength of $63.50 \mathrm{MPa}$, flexural strength of 116.80 $\mathrm{MPa}$, compressive strength of $179.67 \mathrm{MPa}$, and impact resistance Izod of $12.81 \mathrm{~kJ} / \mathrm{m}^{2}$. This result is due to the partially impacted temperature during mechanical stirring; that is why the level of dispersion of nanoclay I.30E particles reached nanosize and the nanoclay I.30E prevented the development of cracks, thus reducing the level of material destruction. When stirring mechanically at 80 degrees $\mathrm{C}$, the nanocomposite material has the highest fire-retardant rate compared with nanocomposite materials; the result is presented in Table 4 .

From Table 4, it was found that the temperature increases and the fire resistance increases (according to UL 94HB method, the burning rate reduced); during the test of combustion with $\mathrm{CH}_{4}$ gas, with gas velocity of $105 \mathrm{ml} / \mathrm{min}$, there was no drip, with fire having small flames for these nanocomposite samples. The formation of a silicate ash layer uniformly spread on the nanocomposite surface prevented the flame penetration process, which caused the combustion process to be extinguished.

Similarly, the method of measuring the burning rate and the LOI method also provided positive results showing the flame-retardant ability of epoxy Epikote 240/nanoclay I.30E nanocomposite materials when the mixture was stirred mechanically at $80^{\circ} \mathrm{C}$.

\subsection{The Effect of Mechanical Stirring Velocity on Mechanical and Flame-Retardant Properties of Epoxy Epikote 240/ Nanoclay I.30E Nanocomposite Materials}

3.3.1. The Effect of Mechanical Stirring Velocity on the Dispersion of Nanoclay I.30E/Epoxy Epikote 240. Optimal 2\% nanoclay I.30E was mixed with epoxy Epikote 240 by mechanical stirring in modes $1500 \mathrm{rpm}, 2000 \mathrm{rpm}$, $2500 \mathrm{rpm}$, and $3000 \mathrm{rpm}$ at $80^{\circ} \mathrm{C}$ for 8 hours, and then ultrasonic stirring was conducted for 60 minutes at $25-30^{\circ} \mathrm{C}$. Results of X-ray diffraction analysis are presented in Figure 5.

From Figure 5, the X-ray diffraction spectrum of the sample with stirring speed of $3000 \mathrm{rpm}$ did not show the characteristic peaks of nanoclay I.30E. It has been proved that there was a high degree of intercalation, and the nanoclays were interwoven in the epoxy E 240 background.

Moreover, the dispersion of nanoclay in epoxy substrate was surveyed by FE-SEM method, and the fracture surface of epoxy Epikote 240/nanoclay I.30E nanocomposite materials is shown in Figure 6. The figure shows that the fracture surface is coarser and shows curved, deviated cracks when there is uniform dispersion of nanoclay I.30E substrates in epoxy Epikote 240 background. This means that the development of cracks was prevented by the nanoclay I.30E which has close bonds with epoxy Epikote 240. When stirring mechanically with lower speed, on the fracture surfaces of materials, there are clusters of nanoclays (bright points on FE-SEM image, Figures 6(a) and 6(b)). It is possible that the mechanical stirring speed is not strong enough to make the dispersion process better. When increasing the stirring speed to $2500 \mathrm{rpm}$, the dispersion level is better but not uniform (Figure 6(c)) compared with the sample in Figure 6(d).

3.3.2. The Effect of Mechanical Stirring Velocity on Mechanical and Flame-Retardant Properties of Epoxy Epikote 240/Nanoclay I.30E Nanocomposite Materials. The effect of mechanical stirring velocity on mechanical properties of epoxy Epikote 240/nanoclay I.30E nanocomposite materials is presented in Table 5 .

From Table 5, when dispersing with a high stirring speed of $3000 \mathrm{rpm}$, mechanical properties are stable and the highest. If the dispersion is not guaranteed at a high mechanical stirring rate, mechanical properties will be degraded in some durability; for samples stirred at $1500 \mathrm{rpm}$, tensile strength decreased to $50.60 \mathrm{MPa}$, with flexural strength of $80.65 \mathrm{MPa}$.

The effect of mechanical stirring velocity on the flame retardancy of epoxy Epikote 240/nanoclay I.30E nanocomposite materials is presented in Table 6. From the table, it was found that the fabricated materials with the dispersion condition in stirring mode of $3000 \mathrm{rpm}$ are high fire-retardant materials (limited oxygen index reached $23.7 \%$, and UL $94 \mathrm{HB}$ was standard).

\subsection{The Study of Ultrasonic Stirring Conditions Affecting the Mechanical and Flame-Retardant Properties of Epoxy Epikote 240/Nanoclay I.30E Nanocomposite Materials}

3.4.1. The Study of the Effect of Ultrasonic Stirring Time on the Mechanical and Flame-Retardant Properties of Epoxy Epikote 240/Nanoclay I.30E Nanocomposite Materials. The energy of ultrasound with the suitable magnitude would make it 


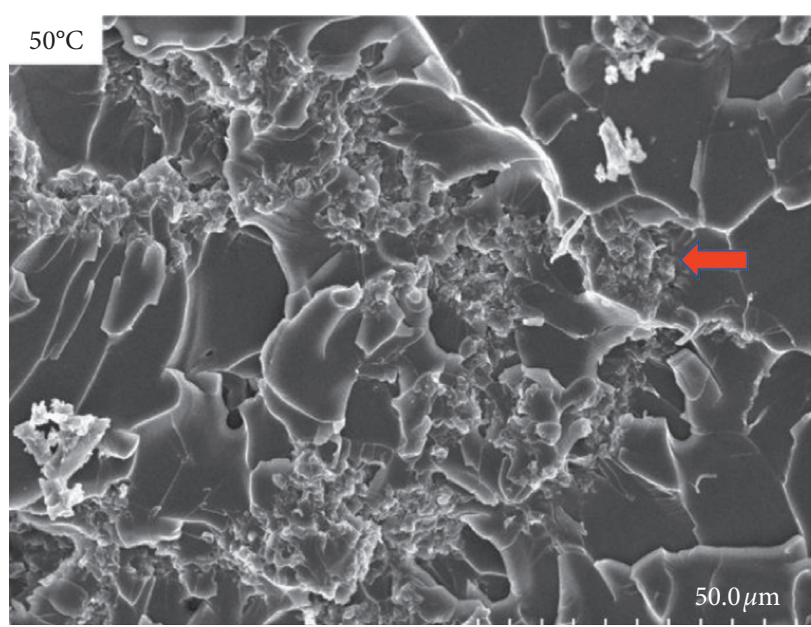

(a)

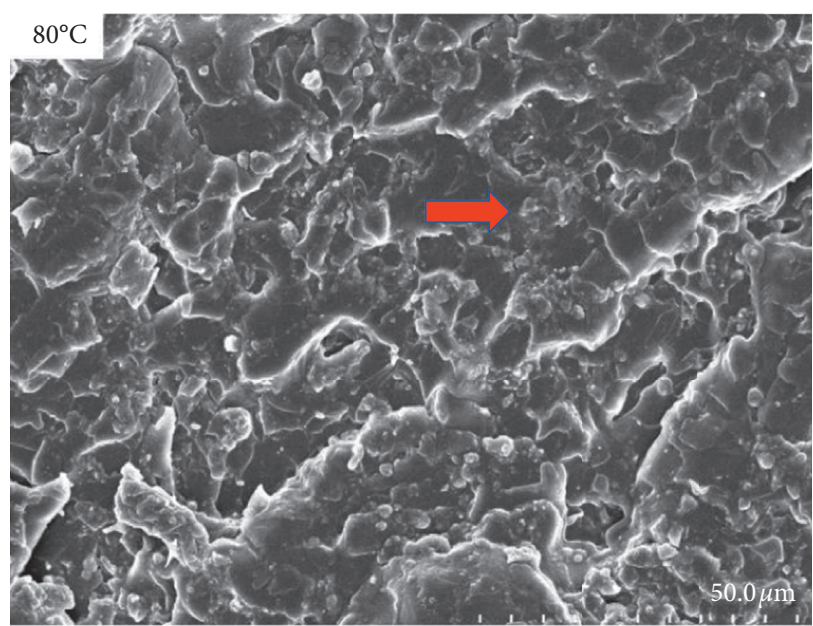

(c)

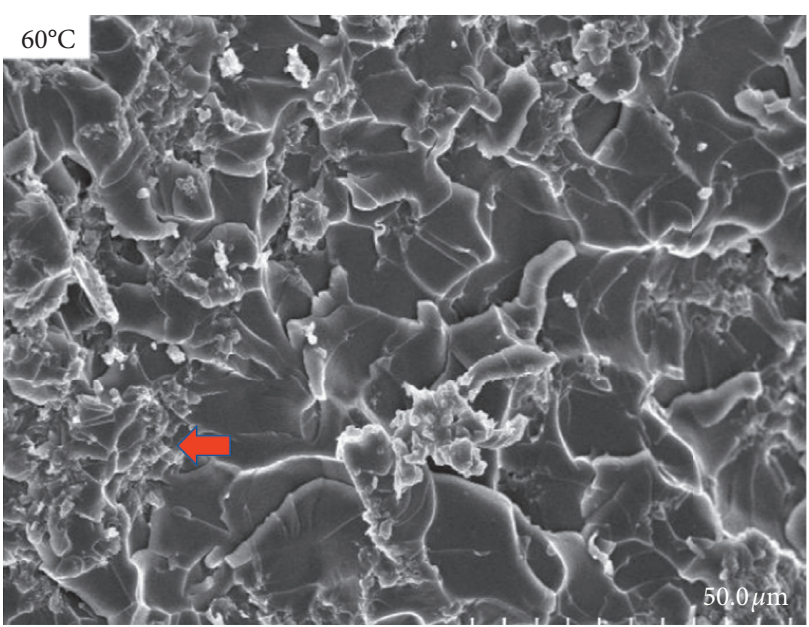

(b)

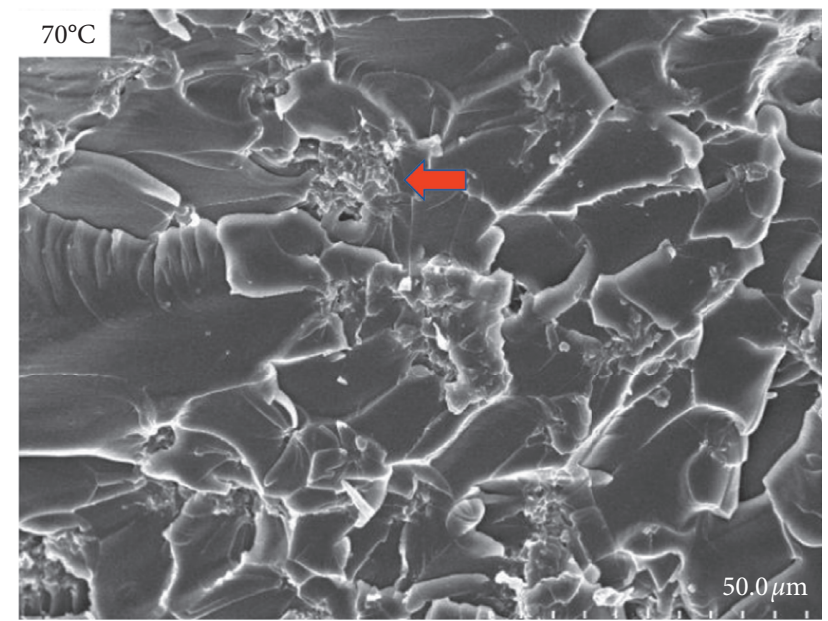

(d)

FIGURE 4: FE-SEM image of broken surface of epoxy Epikote 240 nanocomposite materials mechanically stirred at different temperatures: $50^{\circ} \mathrm{C}, 60^{\circ} \mathrm{C}, 70^{\circ} \mathrm{C}$, and $80^{\circ} \mathrm{C}$.

TABLE 3: Effect of temperature during mechanical stirring on mechanical properties of epoxy Epikote 240/nanoclay I.30E nanocomposite materials.

\begin{tabular}{ccccccc}
\hline No. & $\begin{array}{c}\text { Temperature } \\
\left({ }^{\circ} \mathrm{C}\right)\end{array}$ & $\begin{array}{c}\text { wt\% nanoclay } \\
\text { I.30E }\end{array}$ & $\begin{array}{c}\text { Tensile strength } \\
(\mathrm{MPa})\end{array}$ & $\begin{array}{c}\text { Flexural strength } \\
(\mathrm{MPa})\end{array}$ & $\begin{array}{c}\text { Compressive strength } \\
(\mathrm{MPa})\end{array}$ & $\begin{array}{c}\text { Impact strength } \\
\left(\mathrm{kJ} / \mathrm{m}^{2}\right)\end{array}$ \\
\hline 1 & Neat epoxy & 0 & 55.90 & 86.75 & 156.08 & 7.11 \\
2 & 50 & 2 & 56.60 & 97.65 & 165.09 & 170.70 \\
3 & 60 & 2 & 60.13 & 97.87 & 171.02 & 10.30 \\
4 & 70 & 2 & 60.45 & 98.92 & $\mathbf{1 7 9 . 6 7}$ & 11.50 \\
$\mathbf{5}$ & $\mathbf{8 0}$ & $\mathbf{2}$ & $\mathbf{6 3 . 5 0}$ & $\mathbf{1 1 6 . 8 0}$ & $\mathbf{1 2 . 8 1}$ \\
\hline
\end{tabular}

easier to disperse nanoclay I.30E into epoxy Epikote 240. However, if the ultrasonic duration was prolonged or the capacity of the ultrasound generator was too large, they would adversely affect the structure of plastic and nanoadditives.

The energy of ultrasound with the suitable magnitude with different ultrasonic stirring time is as follows.
(1) The Effect of Ultrasonic Stirring Time on the Dispersion of Nanoclay I.30E in Epoxy Epikote 240 Substrate. After mechanical stirring was finished, ultrasonic stirring was conducted in turn at different time: 30, 45, 60, and 90 minutes, with a capacity value of $50 \%$. The dispersion of nanoclay I.30E in epoxy Epikote 240 was also assessed by FE-SEM method. 
TABLE 4: Effect of temperature during mechanical stirring on fire retardancy of epoxy Epikote 240/nanoclay I.30E nanocomposite materials.

\begin{tabular}{lccccc}
\hline No. & Temperatures $\left({ }^{\circ} \mathrm{C}\right)$ & $\mathrm{wt} \%$ nanoclay I.30E & LOI $\left(\right.$ vol $\left.\% \mathrm{O}_{2} \pm 2 \sigma\right)$ & Combustion rate $(\mathrm{mm} / \mathrm{min})$ & $\mathrm{UL94} \mathrm{HB}(\mathrm{mm} / \mathrm{min})$ \\
\hline 1 & Neat epoxy & 0 & 20.6 & 28.41 & - \\
2 & 50 & 2 & 21.9 & 25.45 & 23.11 \\
3 & 60 & 2 & 22.4 & 25.05 & 23.09 \\
4 & 70 & 2 & 22.4 & 25.70 & 22.98 \\
$\mathbf{5}$ & $\mathbf{8 0}$ & $\mathbf{2}$ & $\mathbf{2 3 . 7}$ & $\mathbf{2 4 . 5 0}$ & $\mathbf{2 2 . 5 9}$ \\
\hline
\end{tabular}

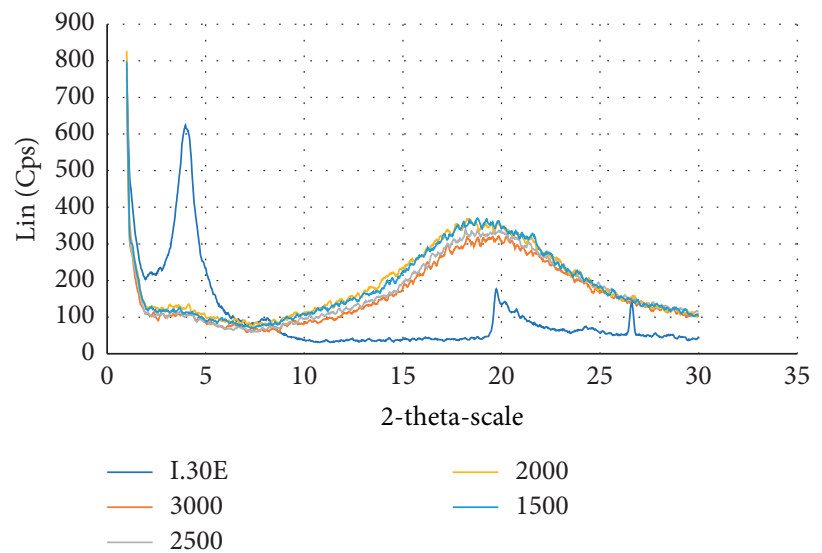

FIGURE 5: XRD diagram of epoxy Epikote 240/nanoclay I.30E nanocomposite at different mechanical stirring speeds: 1500 rpm, 2000 rpm, $2500 \mathrm{rpm}$, and $3000 \mathrm{rpm}$.
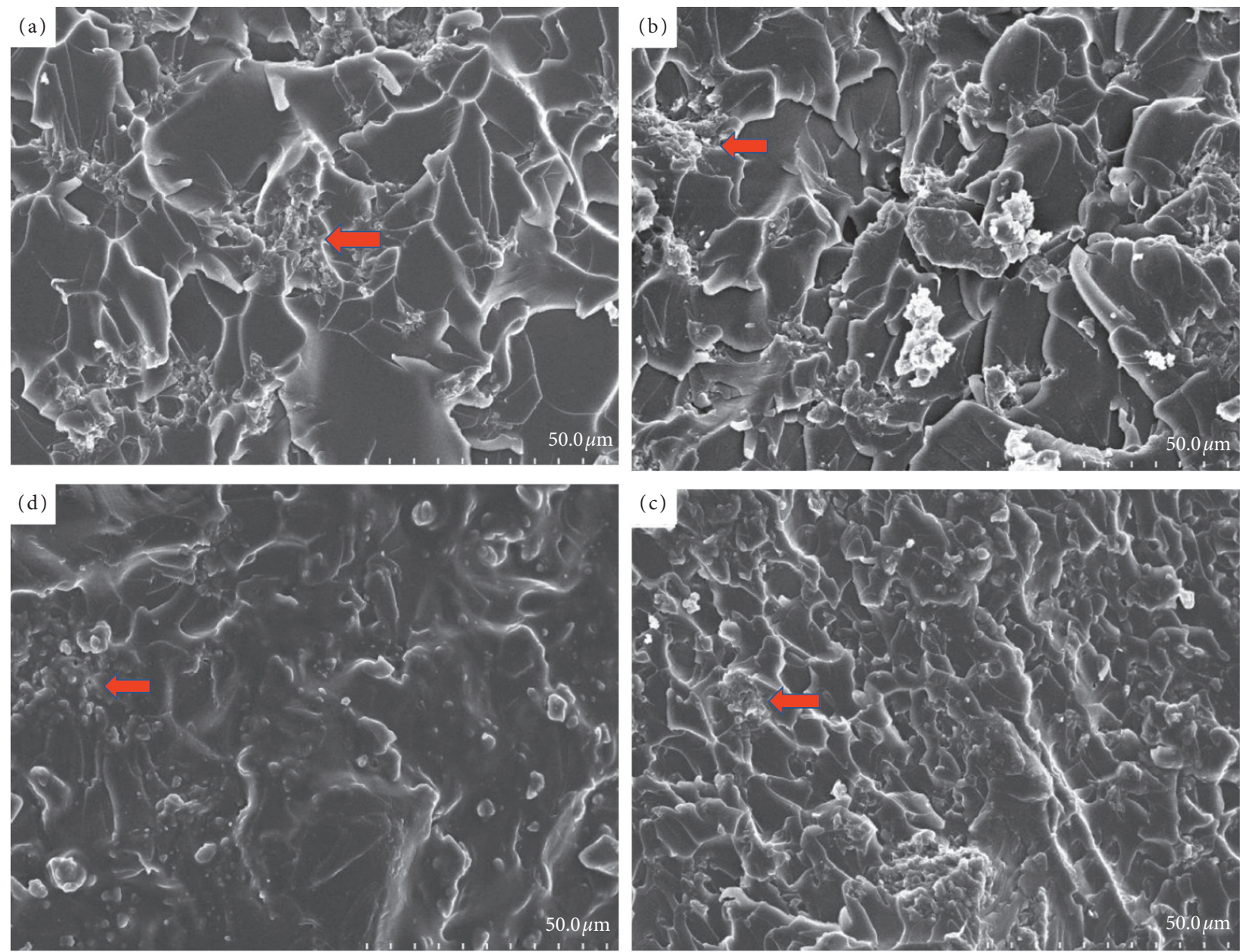

Figure 6: FE-SEM images of E 240/I.30E epoxy nanocomposite samples when stirring at different speeds: (a) $1500 \mathrm{rpm}$, (b) 2000 rpm, (c) $2500 \mathrm{rpm}$, and (d) $3000 \mathrm{rpm}$. 
TABLE 5: Effect of mechanical stirring speed on mechanical properties of epoxy Epikote 240/nanoclay I.30E nanocomposite materials.

\begin{tabular}{lcccccc}
\hline No. & $\begin{array}{c}\text { Stirring } \\
(\mathrm{rpm})\end{array}$ & $\begin{array}{c}\text { wt\% nanoclay } \\
\text { I.30E }\end{array}$ & $\begin{array}{c}\text { Tensile strength } \\
(\mathrm{MPa})\end{array}$ & $\begin{array}{c}\text { Flexural strength } \\
(\mathrm{MPa})\end{array}$ & $\begin{array}{c}\text { Compressive strength } \\
(\mathrm{MPa})\end{array}$ & $\begin{array}{c}\text { Impact strength } \\
\left(\mathrm{kJ} / \mathrm{m}^{2}\right)\end{array}$ \\
\hline 1 & Neat epoxy & 0 & 55.90 & 86.75 & 156.08 & 7.11 \\
2 & 1500 & 2 & 50.60 & 80.65 & 169.23 & 7.00 \\
3 & 2000 & 2 & 55.11 & 93.87 & 170.00 & 172.02 \\
4 & 2500 & 2 & 60.05 & 97.60 & 10.00 & 10.20 \\
$\mathbf{5}$ & $\mathbf{3 0 0 0}$ & $\mathbf{2}$ & $\mathbf{6 3 . 5 0}$ & $\mathbf{1 1 6 . 8 0}$ & $\mathbf{1 7 9 . 6 7}$ & $\mathbf{1 2 . 8 1}$ \\
\hline
\end{tabular}

TABLE 6: Flame-retardant properties of epoxy Epikote 240/nanoclay I.30E nanocomposite materials.

\begin{tabular}{lccccc}
\hline No. & Stirring $(\mathrm{rpm})$ & wt $\%$ nanoclay I.30E & LOI $\left(\right.$ vol $\left.\% \mathrm{O}_{2} \pm 2 \sigma\right)$ & Combustion rate $(\mathrm{mm} / \mathrm{min})$ & UL94 HB $(\mathrm{mm} / \mathrm{min})$ \\
\hline 1 & Neat epoxy & 0 & 20.6 & 28.41 & - \\
2 & 1500 & 2 & 21.9 & 26.55 & 25.11 \\
3 & 2000 & 2 & 21.9 & 25.15 & 25.09 \\
4 & 2500 & 2 & 22.8 & $\mathbf{2 4 . 5 0}$ & 24.08 \\
$\mathbf{5}$ & $\mathbf{3 0 0 0}$ & $\mathbf{2}$ & $\mathbf{2 3 . 7}$ & $\mathbf{2 2 . 5 9}$ \\
\hline
\end{tabular}

The morphology of the fractured surface of nanoclay I.30E/epoxy Epikote 240 nanocomposite materials when stirring ultrasonically at different time is shown in Figure 7.

Figure 7 shows that, when stirring ultrasonically for 30 minutes and 45 minutes for FE-SEM images, two samples of these nanocomposite materials in some areas still have small agglomerations. With the increase of ultrasonic stirring time to 60 minutes, there seems to be no more agglomeration because nanoclay I.30E layers were separated to ensure that epoxy Epikote 240 polymer circuits were inserted between nanoclay I.30E layers. However, when the ultrasonic stirring time was extended to 90 minutes, the dispersion level of nanoclay I.30E into epoxy Epikote 240 was not much improved compared with the 60 minutes of ultrasonic stirring (Figure 7).

(2) The Effect of Ultrasonic Stirring Time on the Mechanical and Flame-Retardant Properties of Nanoclay I.30E/epoxy Epikote 240 Nanocomposite Materials. The results are presented in Table 7.

When the time was extended, the nanoclay I.30E/epoxy Epikote 240 system produced many air traps, and the air would enter more and more at a time, clearly showing that, after stopping the ultrasonic stirring, there were a lot of bubbles on the surface of the glass; in the nanoclay I.30E/ epoxy Epikote 240 material block, this may be the cause of reduced mechanical and flame-retardant properties.

From Table 7, it was found that when the ultrasonic stirring time had an increase of 30 to 60 minutes, the mechanical properties were increased; however, when the ultrasonic stirring time increased to 90 minutes, the mechanical strength properties began to decrease. When adding an external force on the material, the stress would be distributed in the material, causing some mechanical resistance to decrease; for example, the tensile strength decreased from $63.50 \mathrm{MPa}$ to $62.88 \mathrm{MPa}$, and the flexural strength decreased from 116.80 MPa to 97.30 MPa, similar to compressive strength and impact resistance Izod.

The effect of ultrasonic stirring time on the mechanical and flame-retardant properties of epoxy Epikote 240/nanoclay I.30E nanocomposite materials is presented in Table 8. From the table, it was found that the flameretardant properties of the samples are not much different. The sample stirred ultrasonically for 60 minutes has higher fire retardancy than others, but not much.

3.4.2. The Effect of the Working Capacity of the Ultrasonic Stirrer on the Mechanical and Flame-Retardant Properties of Epoxy Epikote 240/Nanoclay I.30E Nanocomposite Materials

(1) The Effect of the Working Capacity of the Ultrasonic Stirrer on the Dispersion of Nanoclay I.30E in Epoxy Epikote 240. XRD spectra of epoxy Epikote 240/nanoclay I.30E nanocomposite materials when ultrasonically stirring with different capacities are shown in Figure 8.

After finishing mechanical stirring, nanoclay was dispersed into epoxy by ultrasound at capacity levels of 25, 50, 75 , and $100 \%$ for 60 minutes.

Results of X-ray diffraction analysis in Figure 8 showed that, basically, when changing the capacity from $25 \%$ to $100 \%$, for the time constant (60 minutes), the dispersion level is not affected.

FE-SEM images of epoxy Epikote 240/nanoclay I.30E nanocomposite materials with different ultrasonic stirring capacities are shown in Figure 9.

Figure 9 showed that using a 50\% maximum capacity of the machine made the structure stable and suitable for dispersing nanoclay in epoxy Epikote 240.

Received results are presented in Table 9.

From Table 9, it was found that, for the ratio of working capacity of ultrasonic stirrers at 50\%, the mechanical strength is maintained at a high level, with tensile strength of $63.5 \mathrm{MPa}$ (increased by $13.59 \%$ ), flexural strength of $116.80 \mathrm{MPa}$ (increased by $34.63 \%$ ), compressive strength of 179.67 $\mathrm{MPa}$ (increased by $15.11 \%$ ), and impact resistance Izod of $12.81 \mathrm{~kJ} / \mathrm{m}^{2}$ (increased by $80.16 \%$ ).

This result is consistent with the XRD survey results and discussion in the structural morphology FE-SEM (Figure 9). 


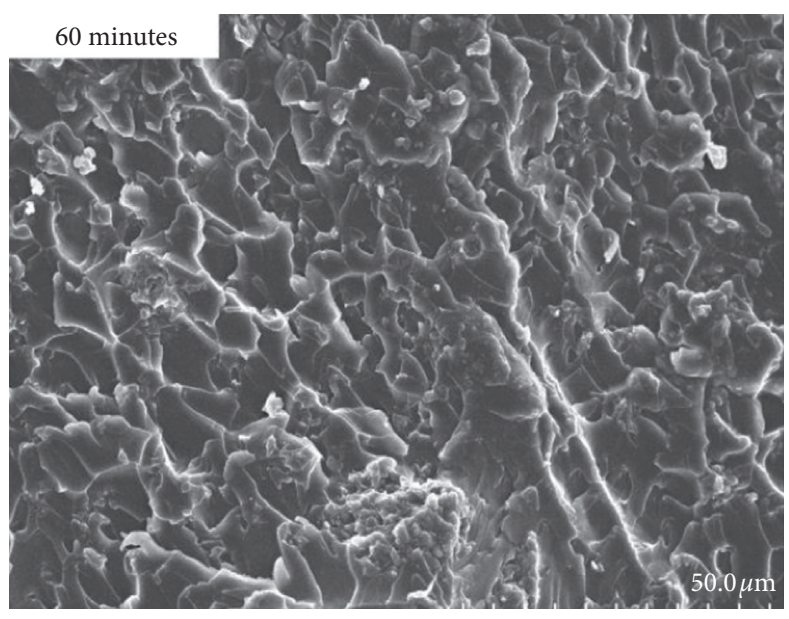

(a)

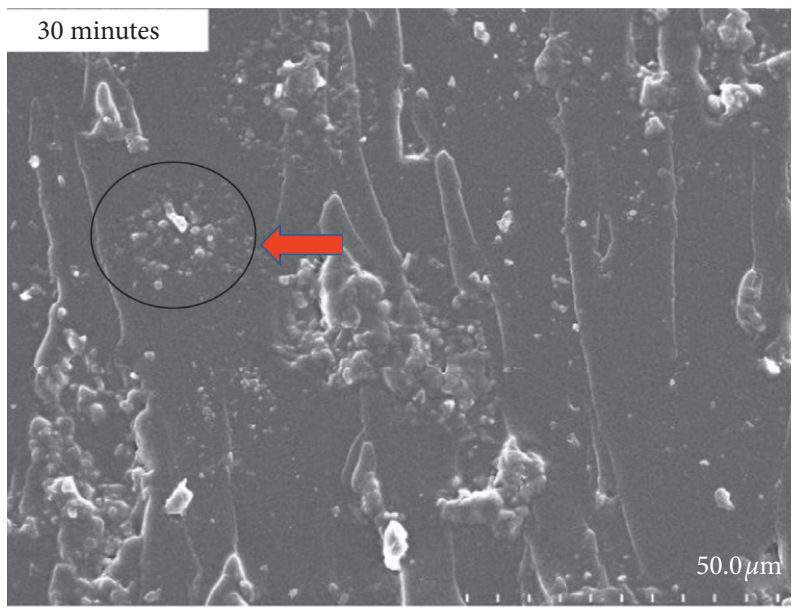

(c)

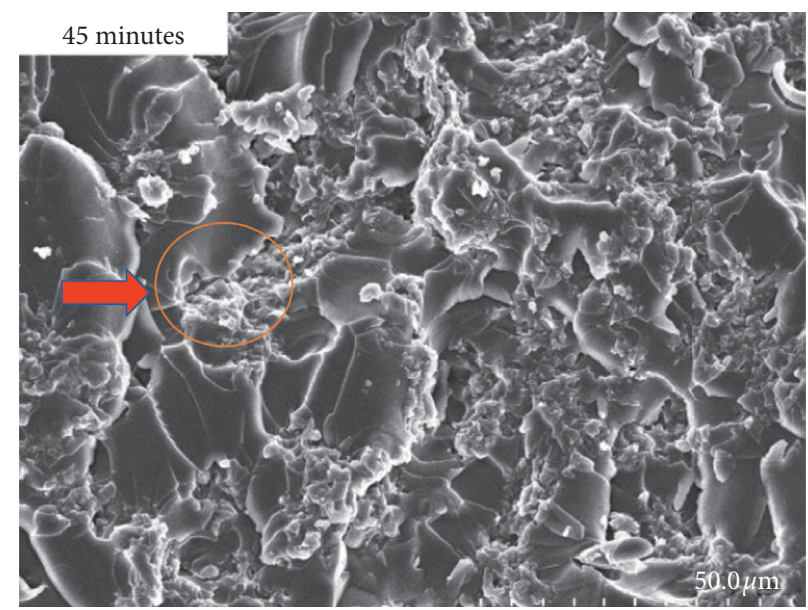

(b)

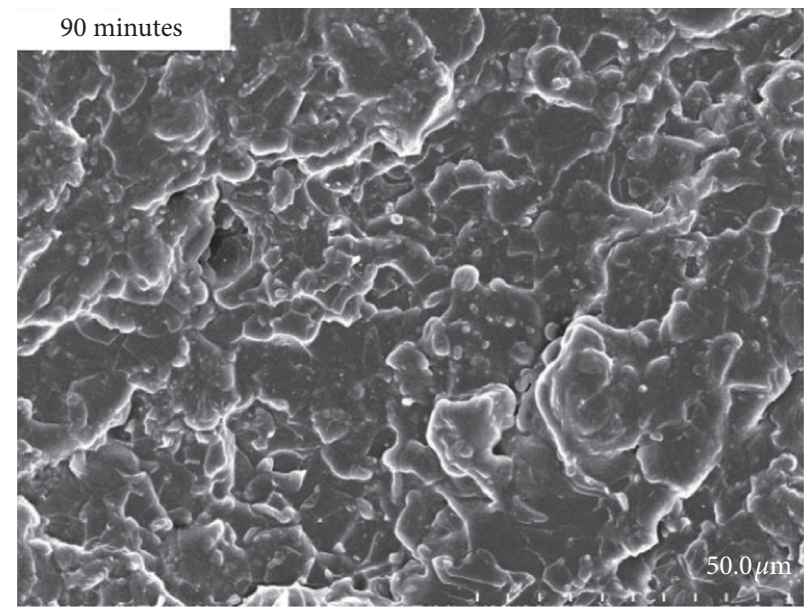

(d)

FIgURE 7: FE-SEM of epoxy Epikote 240/nanoclay I.30E nanocomposite materials.

TABLE 7: Mechanical properties of epoxy Epikote 240/nanoclay I.30E nanocomposite materials.

\begin{tabular}{ccccccc}
\hline No. & $\begin{array}{c}\text { Sonication time } \\
(\mathrm{min})\end{array}$ & $\begin{array}{c}\text { wt\% nanoclay } \\
\text { I.30E }\end{array}$ & $\begin{array}{c}\text { Tensile strength } \\
(\mathrm{MPa})\end{array}$ & $\begin{array}{c}\text { Flexural strength } \\
(\mathrm{MPa})\end{array}$ & $\begin{array}{c}\text { Compressive strength } \\
(\mathrm{MPa})\end{array}$ & $\begin{array}{c}\text { Impact strength } \\
\left(\mathrm{kJ} / \mathrm{m}^{2}\right)\end{array}$ \\
\hline 1 & Neat epoxy & 0 & 55.90 & 86.75 & 156.08 & 7.11 \\
2 & 30 & 2 & 59.88 & 98.00 & 162.18 & 10.31 \\
3 & 45 & 2 & 60.71 & 98.60 & 17.83 & 10.11 \\
$\mathbf{4}$ & $\mathbf{6 0}$ & $\mathbf{2}$ & $\mathbf{6 3 . 5 0}$ & $\mathbf{1 1 6 . 8 0}$ & $\mathbf{1 7 9 . 6 7}$ & 163.23 \\
5 & 90 & 2 & 62.88 & 97.30 & $\mathbf{1 2 . 8 1}$ \\
\hline
\end{tabular}

TABLE 8: Effect of ultrasonic stirring time on fire retardation of epoxy Epikote resin 240/nanoclay I.30E nanocomposite material.

\begin{tabular}{cccccc}
\hline No. & Sonication time $(\mathrm{min})$ & $\mathrm{wt} \%$ nanoclay I.30E & LOI $\left(\right.$ vol $\left.\% \mathrm{O}_{2} \pm 2 \sigma\right)$ & Combustion $\mathrm{rate}(\mathrm{mm} / \mathrm{min})$ & $\mathrm{UL94} \mathrm{HB}(\mathrm{mm} / \mathrm{min})$ \\
\hline 1 & Neat epoxy & 0 & 20.6 & 28.41 & - \\
2 & 30 & 2 & 22.8 & 25.11 & 24.57 \\
3 & 45 & 2 & 22.8 & 24.67 & 23.67 \\
$\mathbf{4}$ & $\mathbf{6 0}$ & 2 & 23.7 & $\mathbf{2 4 . 5 0}$ & 22.59 \\
5 & 90 & 2 & 22.8 & 25.12 & 23.45 \\
\hline
\end{tabular}




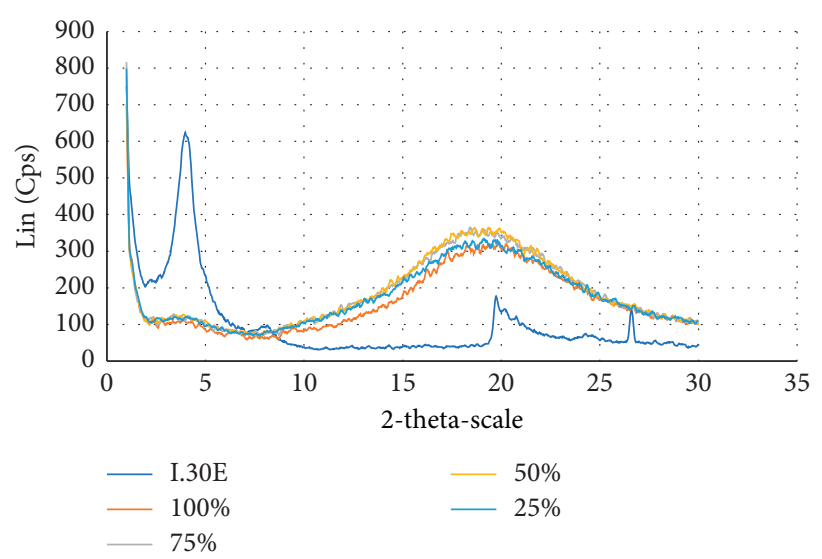

FIGURE 8: XRD diagram of epoxy Epikote 240/nanoclay I.30E nanocomposite material when ultrasonically stirring with different capacities.

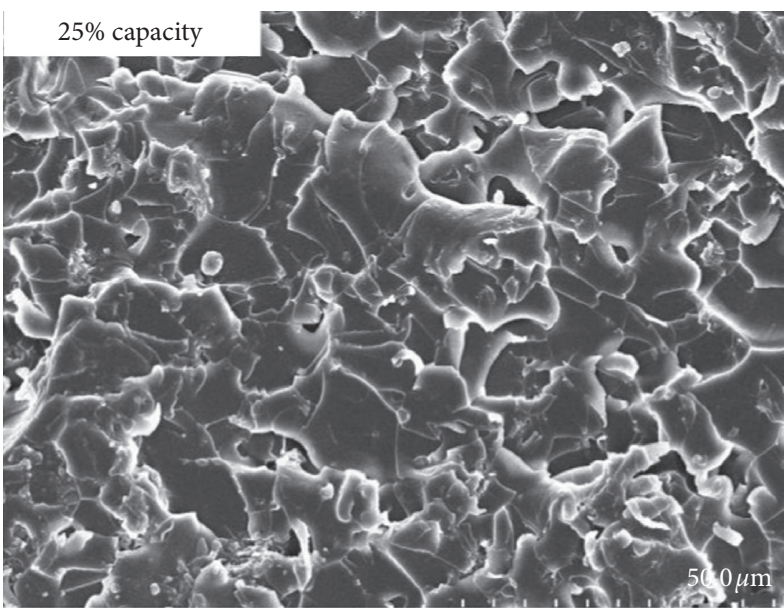

(a)

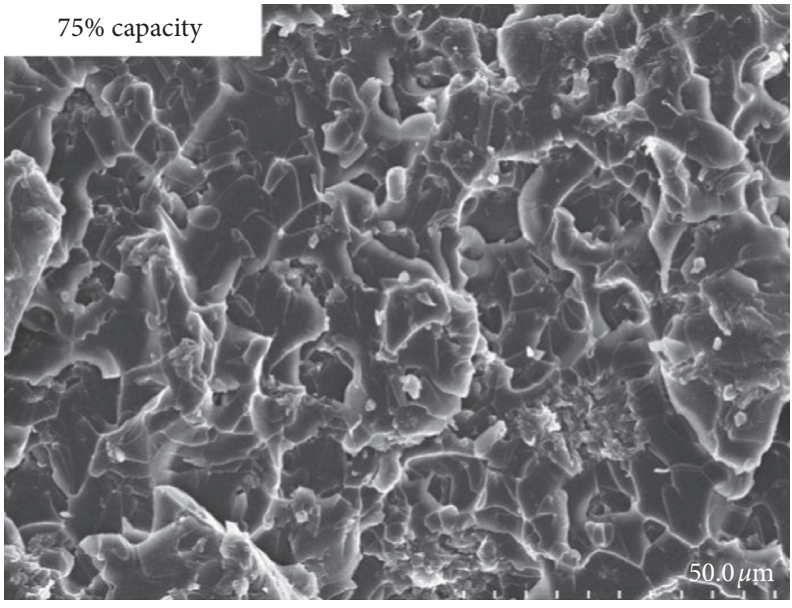

(c)

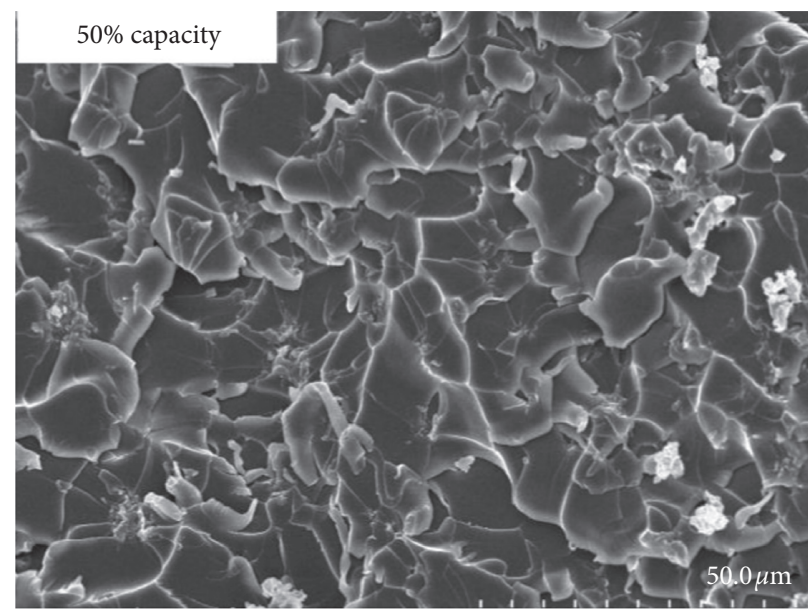

(b)

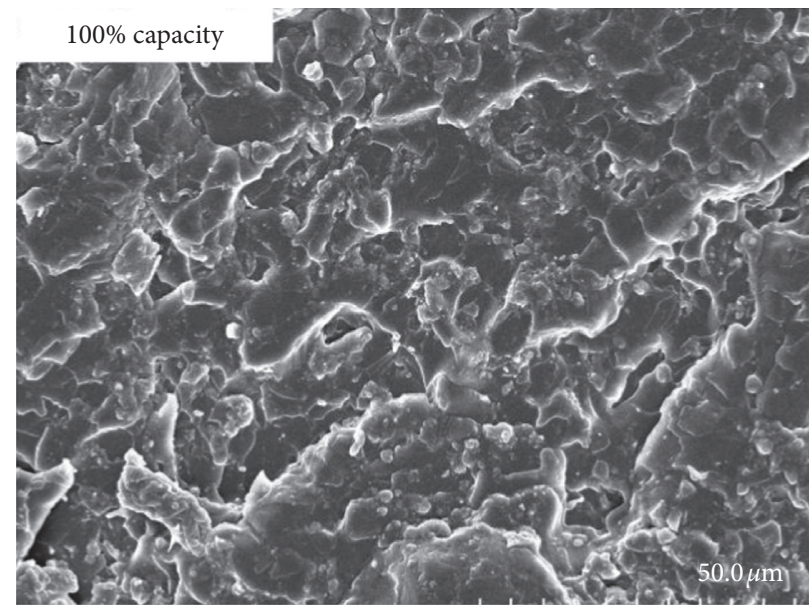

(d)

FIGURE 9: FE-SEM image of epoxy Epikote 240/nanoclay I.30E nanocomposite materials with various ultrasonic stirring capacities: 25 W, $50 \mathrm{~W}, 75 \mathrm{~W}$, and $100 \mathrm{~W}$.

The effect of the working capacity of the ultrasonic stirrer on the flame-retardant properties of epoxy/I.30E nanocomposite materials is presented in Table 10.
From Table 10, it was found that, with a capacity value of $50 \%$ and ultrasonic stirring for 60 minutes, the result was that the flame retardancy of the material reached a high value (LOI 
TABLE 9: Mechanical properties of epoxy Epikote 240/nanoclay I.30E nanocomposite materials with different ultrasonic stirring power.

\begin{tabular}{lccccc}
\hline Power (W, \%) & wt\% nanoclay I.30E & Tensile strength $(\mathrm{MPa})$ & Flexural strength $(\mathrm{MPa})$ & $\begin{array}{c}\text { Compressive strength }(\mathrm{MPa}) \\
\text { Impact strength } \\
\left(\mathrm{kJ} / \mathrm{m}^{2}\right)\end{array}$ \\
\hline E 240* & 0 & 55.90 & 86.75 & 156.08 \\
25 & 2 & 60.53 & 97.21 & 169.58 \\
$\mathbf{5 0}$ & $\mathbf{2}$ & $\mathbf{6 3 . 5 0}$ & $\mathbf{1 1 6 . 8 0}$ & $\mathbf{1 7 9 . 6 7}$ \\
75 & 2 & 62.75 & 98.30 & 175.17 \\
100 & 2 & 61.27 & 97.60 & 176.21 \\
\hline
\end{tabular}

${ }^{*}$ Epoxy Epikote 240 material was solidified by DETA without the addition of nanoclay I.30E (neat epoxy).

TABLE 10: Effect of ultrasonic stirring power on flame-retardant properties of epoxy Epikote 240/nanoclay I.30E nanocomposite material.

\begin{tabular}{lcccc}
\hline Power $(\mathrm{W}, \%)$ & wt $\%$ nanoclay I.30E & LOI $\left(\right.$ vol $\left.\% \mathrm{O}_{2} \pm 2 \sigma\right)$ & Combustion rate $(\mathrm{mm} / \mathrm{min})$ & UL94 HB $(\mathrm{mm} / \mathrm{min})$ \\
\hline E 240 & 0 & 20.6 & 28.41 & - \\
25 & 2 & 22.8 & 24.71 & 24.07 \\
$\mathbf{5 0}$ & $\mathbf{2}$ & $\mathbf{2 3 . 7}$ & $\mathbf{2 4 . 5 0}$ & $\mathbf{2 2 . 5 9}$ \\
75 & 2 & 23.7 & 24.67 & 22.69 \\
100 & 2 & 23.2 & 25.02 & 23.55 \\
\hline
\end{tabular}

index of $23.7 \%$ and combustion rate of $24.50 \mathrm{~mm} / \mathrm{minutes}$; according to $\mathrm{UL} 94 \mathrm{HB}$, the combustion rate reached $22.59 \mathrm{~mm} / \mathrm{min}$ ) compared with materials which were ultrasonically stirred at capacity values of 25,75 , and $100 \%$.

\section{Conclusions}

(i) To disperse nanoclay I.30E in epoxy Epikote 240 reaching the separated and interlaced structure, in this section, the nanoclay I.30E dispersion into epoxy Epikote 240 was investigated by surveying the factors affecting dispersion levels and the appropriate values for the factors which were determined as $2 \%$ nanoclay I.30E by weight dispersed in epoxy Epikote 240 , dispersing at a mechanical stirring rate of $3000 \mathrm{rpm}$ for 8 hours at $80^{\circ} \mathrm{C}$, and then ultrasonic stirring for 60 minutes at room temperature $\left(25-30^{\circ} \mathrm{C}\right)$ with a working capacity of $50 \%$.

(ii) The epoxy Epikote 240/nanoclay I.30E nanocomposite material has mechanical properties and fire retardancy which are improved with only a small amount of nanoclay I.30E (2\% by weight): tensile strength of $63.5 \mathrm{MPa}$ (increased by $13.59 \%$ ), flexural strength of $116.80 \mathrm{MPa}$ (increased by $34.63 \%$ ), compressive strength of $179.67 \mathrm{MPa}$ (increased by $15.11 \%)$, impact resistance Izod of $12.81 \mathrm{KJ} / \mathrm{m}^{2}$ (increased by $80.16 \%$ ), oxygen limit of $23.7 \%$, and combustion rate of $24.5 \mathrm{~mm} / \mathrm{min}$; according to UL $94 \mathrm{HB}$, the combustion rate reached $22.59 \mathrm{~mm} / \mathrm{min}$.

\section{Data Availability}

The data used to support the findings of this study are included within the article.

\section{Conflicts of Interest}

The authors declare that there are no conflicts of interest regarding the publication of this paper.

\section{Acknowledgments}

The authors would like to thank the Faculty of Chemical Technology, Hanoi University of Industry, for funding this work.

\section{References}

[1] T. Kashiwagi, R. H. Harris, X. Zhang et al., "Flame retardant mechanism of polyamide 6-clay nanocomposites," Polymer, vol. 45, no. 3, pp. 881-891, 2004.

[2] C. Kaynak, G. I. Nakas, and N. A. Isitman, "Mechanical properties, flammability and char morphology of epoxy resin/ montmorillonite nanocomposites," Applied Clay Science, vol. 46, no. 3, pp. 319-324, 2009.

[3] C.-K. Lam, H.-y. Cheung, K.-t. Lau, L.-m. Zhou, M.-w. Ho, and D. Hui, "Cluster size effect in hardness of nanoclay/epoxy composites," Composites Part B: Engineering, vol. 36, no. 3, pp. 263-269, 2005.

[4] J. A. M. Ferreira, L. P. Borrego, J. D. M. Costa, and C. Capela, "Fatigue behaviour of nanoclay reinforced epoxy resin composites," Composites Part B: Engineering, vol. 52, pp. 286-291, 2013.

[5] M. D. Tomić, B. Dunjić, V. Likić, J. Bajat, J. Rogan, and J. Djonlagić, "The use of nanoclay in preparation of epoxy anticorrosive coatings," Progress in Organic Coatings, vol. 77, no. 2, pp. 518-527, 2014.

[6] A. A. Azeez, K. Y. Rhee, S. J. Park, and D. Hui, "Epoxy clay nanocomposites-processing, properties and applications: a review," Composites Part B: Engineering, vol. 45, no. 1, pp. 308-320, 2013.

[7] S. Zainuddin, M. V. Hosur, Y. Zhou, A. T. Narteh, A. Kumar, and S. Jeelani, "Experimental and numerical investigations on flexural and thermal properties of nanoclay-epoxy nanocomposites," Materials Science and Engineering: A, vol. 527, no. 29-30, pp. 7920-7926, 2010.

[8] H. Shi, T. Lan, and T. J. Pinnavaia, "Interfacial effects on the reinforcement properties of polymer-organoclay nanocomposites," Chemistry of Materials, vol. 8, no. 8, pp. 15841587, 1996.

[9] S. Lu, W. Hong, and X. Chen, "Nanoreinforcements of twodimensional nanomaterials for flame retardant polymeric 
composites: an overview," Advances in Polymer Technology, vol. 2019, Article ID 4273253, 25 pages, 2019.

[10] F. Guo, S. Aryana, Y. Han, and Y. Jiao, "A review of the synthesis and applications of polymer-nanoclay composites," Applied Sciences, vol. 8, no. 9, p. 1696, 2018.

[11] T. A. Nguyen, Q. T. Nguyen, and T. P. Bach, "Mechanical properties and flame retardancy of epoxy resin/nanoclay/ multiwalled carbon nanotube nanocomposites," Journal of Chemistry, vol. 2019, Article ID 3105205, 9 pages, 2019. 